\title{
Metachromatic Leukodystrophy
}

National Cancer Institute

\section{Source}

National Cancer Institute. Metachromatic Leukodystrophy. NCI Thesaurus. Code C61251.

An autosomal recessive inherited disorder characterized by abnormalities in the development of the myelin sheaths. It is caused by a deficiency of the enzyme arylsulfatase A. There are three forms of this disease: late infantile, juvenile, and adult. In the late infantile form symptoms include muscle weakness and rigidity, gait disturbances, developmental delays, and seizures. In the juvenile form symptoms include gait disturbances, mental deterioration and seizures. The adult form is characterized by psychotic symptoms and dementia. 